\title{
Associação Internacional dos Trabalhadores em Portugal (1871-1873)
}

\author{
International Workingmen's Association in Portugal (1871-1873)
}

\begin{abstract}
João Lázaro*
Resumo: A Associação Internacional dos Trabalhadores surge tardiamente em Portugal. É somente em 1871 que ela contacta com os socialistas portugueses, portanto, num momento em que suas lutas internas eram intensas. As lutas políticas sentidas na Primeira Internacional estarão constantemente presentes na construção da Internacional em Portugal. Este artigo propõe deixar claro como um país periférico, como Portugal, desempenhou um papel importante nas batalhas internas da Primeira Internacional, e explorar os contatos feitos pela Aliança de Democracia Socialista de Mikhail Bakunin, bem como pelo Conselho Geral da Internacional através de Karl Marx e Friedrich Engels. Estas sensibilidades pretendiam conquistar o controle do socialismo português e, de fato, os socialistas portugueses estavam receptivos aos dois campos políticos do internacionalismo.
\end{abstract}

Palavras-chave: Movimento operário; Associação Internacional dos Trabalhadores; classe operária; socialismo.

Abstract: The International Working Men's Association appears late in Portugal. It is only in 1871 that the International contacts occurs with the Portuguese socialists, therefore, at a time when internal differences within the International were intense. The political struggles felt within the First International will be constantly present in the building of the International in Portugal. This article proposes to make clear how a peripheral country, like Portugal, played an important role in the internal battles of the First International, and explore the contacts made by the Alliance of Socialist Democracy of Mikhail Bakunin, as well as by the General Council of the International through Karl Marx and Friedrich Engels. These sensitivities were intended to win the control of Portuguese socialism and, in fact, the Portuguese Socialists will be receptible to the two political fields of internationalism.

Keywords: Workers movement; International Working Men's Association; Working class; Socialism.

Licenciado em História e Mestre em História Moderna e Contemporânea (ISCTE-IUL), bolsista de doutorado em História Moderna e Contemporânea (ISCTE-IUL), financiado pela Fundação para a Ciência e a Tecnologia (FCT) SFRH/BD/110857/2015. Investigador no CIES-IUL. E-mail: joaodizlazaro@gmail.com. ORCID: https://orcid.org/0000-0003-0480-5589. 


\section{Introdução}

A Associação Internacional dos Trabalhadores (AIT) foi fundada em Londres, em 1864, e pretendia funcionar numa lógica federativa, agrupando várias federações e secções de diversos países que estavam sob a égide de um conselho geral. De certa forma, a AIT era uma associação homogênea, com diversos grupos ancorados à defesa do socialismo, mas, por outro lado, bastante heterogénea, pois tinha sensibilidades distintas e contraditórias nas suas fileiras. As correntes de PierreJoseph Proudhon, Mikhail Aleksandrovitch Bakunin, Ferdinand Lassalle, Giuseppe Mazzini e de Karl Marx tinham forte influência na vida da AIT. Ou seja, uma associação ambígua, estruturada na aliança entre diferentes tipos de socialismos que, na prática, eram rivais e concorrentes. De certa forma, é possível aplicar um sentido ecuménico à Internacional, no sentido dado por Eric Hobsbawm à Revolução Francesa. A Internacional tinha o propósito de colocar vários agentes em contato com os diversos movimentos operários internacionais e, desse modo, implantar uma rede de circulação de ideias, pessoas e contatos em nome de uma revolução social internacional. Rapidamente, a AIT consegue expandir uma forte preponderância em vários países europeus, nomeadamente, em Inglaterra, França, Itália, Bélgica, Suíça e Espanha. Em comparação com esses países, Portugal tinha uma taxa de industrialização baixa e um pioneiro processo iniciado em 1851 (Regeneração) que vai implantar, no território, uma forte dinâmica capitalista com o surgimento de novas reformas, a construção de novas vias de comunicação (entre elas os caminhos-deferro), que faz desencadear o aparecimento da fábrica em larga escala e o aumento do vapor, embora a pequena oficina continue a ter uma forte presença no setor produtivo. No entanto, a ausência da industrialização não inviabilizou em Portugal o surgimento de um movimento operário cultural e politicamente semelhante aos movimentos operários das potências industriais. Todavia, a entrada da Internacional em Portugal é acentuadamente tardia, só ocorre em 1871. Até então o movimento operário e o movimento socialista português estavam enquadrados e integrados na sociedade liberal. Desde 1851, que a primeira grande geração de socialistas portugueses, totalmente embebida nas ideias do socialismo utópico, tinha estabelecido uma aliança com setores liberais progressistas, munindo o movimento operário com uma roupagem ordeira e conciliadora, afastando desse modo os trabalhadores de comportamentos revolucionários. Em 1852, é edificado o Centro Promotor do Melhoramento das Classes Laboriosas, através da aliança de socialistas

Confrontar, HOBSBAWM, Eric. A era das revoluções. Lisboa: Editorial Presença, 2001. 
utópicos (Sousa Brandão, Lopes de Mendonça e Vieira da Silva) com liberais progressistas. O primeiro presidente dessa associação será o importante liberal Rodrigues de Sampaio ${ }^{2}$ e até 1871 vai ser a principal organização do movimento operário. É uma associação operária que estará constantemente em diálogo com o regime liberal, salvaguardando o mundo operário de qualquer teor violento ou reivindicativo, e que pretendia apenas fornecer auxílio, amparo e educação ao trabalhador. De facto, o "Centro Promotor opta por uma roupagem estritamente ordeira e conciliadora".3

Neste artigo pretendemos abordar a história da Internacional em Portugal, um país periférico com baixa taxa de industrialização, mas que mesmo assim não deixou de integrar a história da Internacional. Entre 1871 a 1873 a Internacional emergia em Portugal e rapidamente as divergências internas são sentidas; desse modo, Portugal passa a ser outro palco para as lutas entre marxistas e bakunistas.

\section{Os primeiros contatos com os internacionalistas}

A entrada da Internacional em Portugal ocorre através de três importantes internacionalistas espanhóis: Anselmo Lorenzo, Tomás Morago e Francisco Mora, dirigentes do conselho Espanhol da AIT, que durante um curto espaço vão viver em Lisboa devido às perseguições políticas em Espanha. Em 1871, decidiram sair de Toledo rumo ao deserto da Mancha e, através da Extremadura, cruzaram a fronteira. James Guillaume, importante dirigente da AIT, confirma esta tese: "em 1871, quando as perseguições forçaram três membros do Conselho Federal, Morago, F. Mora e Lorenzo, [refugiaram-se] em Lisboa", ${ }^{4}$ para em seguida contar que na capital portuguesa "constituíram um núcleo do grupo de Madrid da Aliança". ${ }^{5}$ Embora a vinda dos internacionalistas a Lisboa tenha sido forçada, na verdade, já era sentida na AIT uma necessidade de estabelecer contatos com Portugal. Anselmo Lorenzo escreve nas suas memórias que, em dezembro de 1870, o movimento internacionalista espanhol pretendia estabelecer ligações com o movimento operário português, uma vontade afirmada publicamente num congresso de operários em Barcelona, onde é anunciado um apelo aos trabalhadores portugueses para a construção da

2 Como ministro do Reino, em 1871, vai se envolver numa polémica com o Centro Promotor, devido aos debates em torno da Comuna de Paris e a Internacional.

3 LÁZARO, João. O despontar do movimento operário português na esfera pública. Das práticas ao debate parlamentar (1850-1860). Lisboa: Chiado Editora, 2014. p. 188.

4 GUILLAUME, James. L'Internationale: documents et souvenirs (1864-1878). Paris: Sociéte Nouvele de Libraire et D’Edition, 1905. p. 27.

5 Ibidem, p. 271. 
Internacional. ${ }^{6}$ Mais tarde, Friedrich Engels escrevia uma carta ao Conselho Federal Espanhol, salientado a importância de formar uma secção da Internacional em Portugal, deixando um apelo aos espanhóis: "não temos ainda secção em Portugal, porventura é mais fácil para vocês do que para nós encetar relações com os trabalhadores desse país". ${ }^{7}$

Os três internacionalistas espanhóis chegam a Lisboa em junho de 1871. Anselmo Lorenzo afirma não se "lembra[r] como foi estabelecido o contato com [José] Fontana e Antero de Quental, mas as primeiras reuniões foram realizadas na casa do segundo", 8 ao passo que Francisco Mora relata no seu livro o conhecimento prévio da existência do Centro Promotor, uma associação "muito semelhante ao Fomento de las Artes de Madrid, [onde] na qual conquistamos a amizade de José Fontana, operário nascido na Suíça". ${ }^{9}$ A chegada dos espanhóis coincide com uma clivagem política no Centro Promotor, onde o surgimento de uma nova e jovem geração de socialistas (José Fontana, Antero de Quental, Nobre França, José Tedeschi, Jaime Batalha Reis, João Bonança, entre outros) reivindicava um discurso mais aguerrido e agressivo perante 0 regime liberal. O socialismo ordeiro, até então dominante, começava a perder força no mundo operário português, muito em parte aos ecos da Internacional e, sobretudo, da Comuna de Paris de 1871. Portanto, é uma realidade conflituosa e contraditória que os internacionalistas espanhóis vão encontrar no movimento operário português, mas perfeita para atrair os socialistas mais radicais para a causa internacionalista. Os primeiros contatos são feitos com José Fontana, Antero de Quental e Jaime Batalha Reis. Este último relata nas suas memórias que certa noite Fontana e Quental apareceram com os três emissários da Associação Internacional dos Trabalhadores, para, em seguida, delinearem "um plano de vasta organização, expuseram as doutrinas de Karl Marx, e as teorias ...que dividiam o socialismo nascente". ${ }^{10}$ Ficaram decididos novos encontros, no entanto, José Fontana, desconfiado que a polícia estava a observar os seus movimentos, acabou por propor que as futuras reuniões fossem realizadas na privacidade de um barco no rio Tejo. Assim, Jaime Batalha Reis e Antero Quental alugaram um barco e combinaram o encontro num outro cais com José

6 Citado em: LORENZO, Anselmo. El proletariado militante: memorias de un internacionalista. [S. I.]: Biblioteca Virtual Antorcha, 2008. p. 140. Disponível em: http://www.antorcha.net/biblioteca_virtual/historia/proletariado/indice.html. Acesso em: 15 mar. 2018.

7 AAVV. Friedrich Engels to the Spanish Federal Council of the International Working Men's Association. Marx \& Engels Collected Works. Letters 1870-71. v. 22. [S. I.]: Lawrence \& Wishart Electric Book, 2010. p. 279.

8 LORENZO, op. cit., p. 183.

9 MORA, Francisco. Historia del socialismo obrero español. Desde sus primeras manifestaciones hasta nuestros días. Madrid: Imp. de I. Calleja, 1902. p. 89.

10 MINÉ, Elza. Alguns homens de meu tempo e outras memórias de Jaime Batalha Reis. Coimbra: Imprensa da Universidade de Coimbra, 2017. p. 118. 
Fontana e os internacionalistas. Batalha Reis romantizou para a eternidade esses encontros: "durante horas, nessa noite e nas seguintes, sobre o Tejo, enquanto eu remava, o Antero discutia, com os emissários socialistas, a revolução operária que já lavrava na Europa". ${ }^{11}$ Nessas reuniões, ficou estabelecida a necessidade de envolver outros socialistas com o fim de formar um núcleo organizador da Internacional em Portugal. Deste modo, o núcleo internacionalista de Lisboa foi expandido a outras individualidades, como "Eduardo Maia, Nobre França, Tedeschi, Tito, Soares Monteiro, Gonçalves Lopes, Azedo Gneco". ${ }^{12}$

A estada dos internacionalistas espanhóis é balizada entre junho e agosto de 1871 e caracterizada, por um lado, pela edificação de estruturas internacionalistas em Lisboa e, por outro, por profundas divergências internas. Morago, o mais próximo da Aliança da Democracia Socialista de Bakunin, entra em conflito com os outros dois espanhóis, acabando por apresentar a demissão do conselho espanhol e opta por prolongar a sua estada em Portugal. Os outros dois vão regressar a Espanha para participar de um encontro da Internacional em Valência. Nessa fase, Anselmo Lorenzo e Francisco Mora revelam uma postura intermédia, nomeadamente Mora, que tinha ligações com Bakunin, mas não deixava de contactar regularmente com o conselho geral em Londres, particularmente, com Engels. É de crer que será através deste espanhol que se estabelece os contatos entre os socialistas portugueses e Engels, que, desde 1870, "estava encarregado da correspondência com Espanha, Portugal e Itália". ${ }^{13}$ Francisco Mora também é, dos três, o que transparece um maior otimismo pela missão em Portugal, escrevendo uma carta a Engels na qual vaticinava a expansão da Internacional para a América Latina através dos portugueses, "graças aos quais a AIT será levada ao Brasil [e a] possível fundação de uma série de federações regionais em Buenos Aires, Montevidéu e Valparaiso". ${ }^{14}$ Os dirigentes da Internacional observam Portugal como um ponto chave na expansão da Internacional para o Brasil, devido às especificidades culturais e linguísticas.

A presença da Internacional não passa despercebida na esfera pública portuguesa. Constantemente, os jornais divulgam notícias sobre a presença da Internacional no território, por vezes exageradas. É o caso do Diário de Notícias que chegou a relatar a existência de 100 decúrias da Internacional em Portugal. A Revolução de Setembro afirmava que a Internacional era uma realidade, havendo

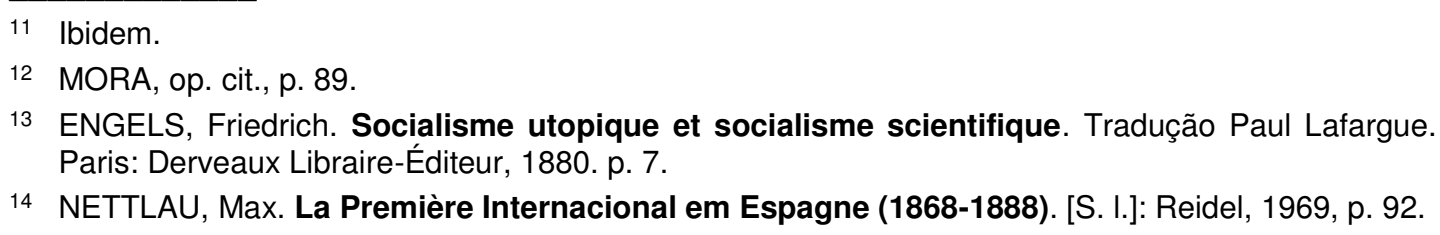


agentes disseminados pelo país, "principalmente em Lisboa". ${ }^{15} \mathrm{O}$ jornal não estava enganado em relação a Lisboa, onde os internacionalistas espanhóis continuavam a realizar avanços na concretização de um núcleo da Internacional em Portugal. No final de 1871, o Jornal do Comércio anunciava que os estatutos da Internacional estavam a ser divulgados em Portugal, estando já um exemplar na posse das entidades governamentais e alertando o leitor que os estatutos estavam habilmente redigidos, com clareza e simplicidade "de forma a seduzir e arrastar as classes operárias". ${ }^{16}$

\section{A influência da Internacional no movimento operário português}

A presença dos espanhóis faz germinar vários grupos, mais ou menos secretos, que se apresentam como legítimos representantes da Internacional em Portugal. A entrada da Internacional no país vai contribuir de forma decisiva para o nascimento de um novo tipo de associativismo operário, as associações de resistência. Por um lado, temos o grupo do antigo padre João Bonança, onde a Aliança era preponderante, responsável pela edificação da primeira associação de resistência em Portugal: a Associação Protectora do Trabalho Nacional (APTN). É esta associação que abriga o primeiro núcleo da Internacional em Portugal, orientado "pelo programa da Aliança Internacional da Democracia Socialista"17 e não pelos estatutos da própria AIT. Os importantes socialistas José Fontana e Antero de Quental vão participar deste grupo e o próprio Quental reconhece a existência da Aliança numa carta para Jaime Batalha Reis: "Da Aliança tenho a dar-lhe as melhores notícias ...já definitivamente constituída, e com bons elementos. Vai publicar-se um jornal, que seja o órgão do programa da mesma, lá para janeiro". ${ }^{18}$ Antero de Quental, importante intelectual desse período, assume as ideias socialista, demonstra ser um fervoroso apoiante da Internacional e, mais tarde, passa a militante do Partido Socialista Português. É ele o responsável pela publicação de um manuscrito intitulado $O$ que é a Internacional?, publicação que pretendia divulgar no espaço público as ideias da AIT e adquirir fundos para as despesas da organização local. Curiosamente, esse livro é objeto de uma tradução para o castelhano e publicado em

15 A revolução de Setembro, 8 jul. 1871, XXXII Ano, n. 8717. p. 2.

16 Jornal do Comércio, 10 dez. 1871, 18. Ano, n. 5437. p. 1.

17 NOGUEIRA, César. Notas para a história do socialismo em Portugal (1871-1910). Lisboa: Portugália Editora, 1967. p. 33.

18 STAACK, Maria (org). Correspondência entre Antero de Quental e Jaime Batalha Reis. Lisboa: Assírio e Alvim, 1982. p. 62. 
Espanha, em 1872. O nome de Antero de Quental não aparece no livro, no seu lugar surge o da Comissão de Propaganda do Núcleo Organizador da Internacional em Lisboa, que "merece por este trabalho o bem do proletariado". ${ }^{19}$ No entanto, vários socialistas acabam por se afastar desse grupo, como é o caso de Antero de Quental e José Fontana; e o próprio João Bonança acaba por perder a influência que tinha no mundo operário, quando é dado como aliado político de altas figuras do liberalismo português, acabando, posteriormente, por trocar o socialismo pelo republicanismo.

Por outro lado, temos os internacionalistas portugueses próximos ao denominado socialismo científico de Karl Marx e Friedrich Engels, encabeçado pelo tipógrafo Nobre França, que vai ser durante alguns anos o contato de Engels em Portugal. José Fontana apresenta um comportamento ambíguo, apoiando inicialmente a Aliança, mas acaba por aderir ao campo do conselho-geral da Internacional. No relatório de maio de 1873 , da autoria de um polícia francês (Latour) - enviado a Portugal para investigar a Internacional e procurar refugiados da Comuna de Paris - consta que numa "reunião foi proposto excluir da Internacional [José] Fontana, [Antero de] Quental, [Eduardo] Maia e um livreiro ...Carrilho [Videira]". ${ }^{20}$ Latour afirma que, dessa reunião, Fontana e Carrilho acabam afastados da Internacional sob o pretexto de estarem em ligação à Aliança. No entanto, não encontramos nenhuma documentação a atestar as expulsões, antes pelo contrário, tudo indica que José Fontana manteve a sua ligação à Internacional. A própria Internacional em Espanha, dominada pela Aliança, não depositava confiança em José Fontana. Por exemplo, em junho de 1873, circulava um ofício interno nos meios internacionalistas espanhóis onde eram expressas suspeitas sobre os líderes portugueses da Internacional, afirmando que a entidade era dirigida por José Fontana, fazendo a "advertência que eram companheiros, infelizmente, autoritários e segu[iam] as pegadas do Conselho Geral" ${ }^{21}$ O próprio José Fontana, em finais de 1873, chega a escrever uma carta a Karl Marx, onde se declara seu admirador ${ }^{22}$ e solicita, ao pensador marxista, textos da sua autoria a serem lidos num sarau socialista de apoio a alguns trabalhadores que tinham participado da greve dos trabalhadores, na indústria de tabaco em 1872. O Protesto, jornal socialista, ao

19 COMISION de propaganda del núcleo organizador de la Internacional en Lisboa. Lo que es la Internacional. Madri: Imprenta de J. Antonio Garcia,1872. p. 4.

20 FREYMOND, Jacques (Dir). La Première Internationale. Les conflitos au sein de I'Internationale 1872-1873. Tomo III. Genève: Publications de I'Institut Universitaire de Hautes Études Internationales, 1971. p. 416.

21 SAS, Teresa Martínez de. Cartas, comunicaciones y circulares de la comision federal de la region española (Junio-Septiembre 1873). v. 5. Barcelona,1979. p. 77.

22 Carta de José Fontana para Karl Marx, 26 de dezembro de 1873. In: Karl Marx/Friedrich Engels Papers, 1704, International Institute of Social History, p. 28. 
escrever sobre o suicídio de José Fontana, traça o seu percurso trepidante, lembrando que de início filiou-se "na escola do celebre socialista russo Miguel Bakounine, fazendo parte da seção de Lisboa da Aliança da Democracia Socialista"23 mas que foi dissolvida mais tarde, "quando melhor se compreendeu o movimento revolucionário dos operários socialistas". ${ }^{24}$ José Fontana é de facto uma figura incontornável do movimento operário português. Nascido no cantão de Ticino, não se sabe ao certo a data em que entrou em Portugal, apenas que no país tem uma ascensão social notável. Inicialmente é empregado como trabalhador na livraria Bertrand, onde acabou por se tornar sócio-gerente. Nas décadas de 1970 e 1980 do século XX, ocorreu um debate historiográfico em torno da identidade desse socialista. Alguns historiadores ${ }^{25}$ defendem que Fontana é na verdade Giuseppe Fontana que, entre 1864-65, havia integrado o conselho geral da AIT em Londres, em representação dos socialistas italianos. Existem argumentos válidos para ambos os lados. Por um lado, há suspeita de ser uma mera coincidência a existência de dois Fontanas italianos com ligação à Internacional. Muito pouco se conhece da vida de Fontana em Portugal até 1870: sabia escrever em inglês e demonstrava certa politização e certo conhecimento sobre a Internacional. Por outro, temos acesso à correspondência da Internacional, no Instituto de História Social (Holanda), onde é possível verificar que em 1865 Guiseppe Fontana escreveu uma carta para Marx em que a caligrafia e a assinatura diferem das cartas que José Fontana escreveu de Portugal para Marx e Engels. José Fontana suicidou-se em setembro de $1876 \mathrm{e}$ nunca abordou o seu passado e não deixou registos escritos sobre um eventual percurso por Londres. Depois da sua morte, nenhum dos escritos dos seus companheiros referem essa estada, portanto, é de crer que nunca tenha comentado com os companheiros. De igual modo, tanto Marx como Engels não deixaram nada escrito indicando que o Fontana de Portugal fosse o mesmo Fontana de Londres. Seja como for, vamos acreditar que hipoteticamente estamos perante a mesma pessoa. Assumindo este pressuposto, devemos realizar uma questão que a historiografia nunca abordou. Qual é o contributo de José Fontana e o seu passado para a história do socialismo e da Internacional em Portugal? Por outras palavras, qual é a importância de ter um antigo elemento do primeiro conselho da Internacional em Lisboa? Podemos então concluir com segurança que foi absolutamente nada.

\footnotetext{
O Protesto, set. 1876, II ano, n. 56. p. 1.

24 Ibidem.

25 Vasco Magalhães-Vilhena foi o primeiro a defender a dupla identidade de José Fontana em 1964. Mais tarde, historiadores como Carlos da Fonseca, Jacinto Rodrigues, Ramiro da Costa, César de Oliveira, Fernando Piteira Santos, António Silva Leal, Maria Manuela Cruzeiro, João Arsénio Nunes, Maria Filomena Mónica e Alberto Vilaça entraram no debate, apresentando argumentos a favor e contra.
} 
José Fontana nunca tirou proveito da sua bagagem e experiência política em Inglaterra para implantar em Portugal a Internacional. Não há um nexo de causalidade entre a eventual presença de um antigo dirigente do conselho geral da AIT em Lisboa, com a sua germinação. Sabemos que a equação da Internacional em Portugal é o somatório de três variáveis; os internacionalistas espanhóis em Lisboa, um desejo do conselho geral em entrar em Portugal e um movimento operário português permeável às ideias socialistas da Internacional. Portanto, o debate em torno da dupla identidade de José Fontana acaba por ser uma mera curiosidade histórica do movimento operário português.

O grupo português ligado ao marxismo acaba por fundar, em 1872, a segunda e a mais importante associação de resistência em Portugal, denominada Fraternidade Operária. Esta associação vai ser responsável pela dinamização de um importante jornal operário, O Pensamento Social. A associação e o jornal são dois marcos de enorme importância na história do trabalho portuguesa. Se a Fraternidade Operária tem sido encarada pela historiografia como uma "obra criada pelo esforço dos internacionalistas", ${ }^{26}$ o Pensamento Social tem escapado a essa análise. Esse jornal é também um íntimo produto do internacionalismo, visto que é claramente inspirado no jornal internacionalista publicado em Espanha, o La Emancipación. Este jornal espanhol é descrito por Engels como, "porventura, o melhor jornal que a Internacional possuía". ${ }^{27}$ Os socialistas portugueses chegam a estampar o mesmo lema do La Emancipación ("No mas derechos sin deberes. No mas deberes sin derechos"), em O Pensamento Social: "Não mais deveres sem direitos, não mais direitos sem deveres". Portanto, não é de estranhar que altas figuras da Internacional fizessem rasgados elogios aos avanços do socialismo português. Engels foi um dos mais ativos nesses elogios. À sua luz, não havia dúvida que o jornal O Pensamento Social contava com enorme qualidade nos textos, ficando surpreso por encontrar esse tipo de jornal em "um canto tão remoto do mundo". ${ }^{28} \mathrm{Em}$ abril de 1873, Engels escrevia ao conselho geral da Internacional, elogiando os socialistas portugueses pelo "Pensamento Social de Lisboa [como] um excelente jornal". ${ }^{29}$

O período de 1872-73 é singular na história do movimento operário português devido à ação grevista, particularmente em Lisboa e no Porto. A Fraternidade Operária vai dirigir as greves no setor dos tabacos, caminhos-de-ferro e no setor do

26 FONSECA, Carlos da. A origem da 1aㅡ Internacional em Lisboa: o centenário da Federação Portuguesa. Lisboa: Editorial Estampa, 1973. p. 56.

27 AAVV. Marx \& Engels Collected Works. Marx and Engels 1871-74. v. 23. [S. I.]: Lawrence \& Wishart Electric Book, 2010. p. 292.

28 Ibidem, p. 340.

29 Ibidem, p. 438. 
ferro em Lisboa. É preciso notar que a prática grevista estava proibida pelo código penal e vai motivar um debate no espaço público. Constantemente, a Fraternidade Operária é acusada pelos jornais de estar ao serviço da Internacional. De facto, a associação era indissociável do internacionalismo, pois os seus dirigentes eram membros da Internacional e havia íntimos contatos com ela, nomeadamente, através de diversa correspondência que enaltecia a solidariedade internacional entre trabalhadores e solicitava um trabalho para impedir o envio de trabalhadores estrangeiros para Portugal, no sentido de ocupar os lugares dos grevistas. Todavia, o período grevista vai infligir um negativo impacto na organização da Fraternidade Operária, principalmente em nível financeiro e o seu sucesso é limitado. Por exemplo, os trabalhadores associados à Fraternidade são perseguidos pelos patrões, que impõem como condição de regresso ao trabalho o fim da militância na referida associação. Somente no setor da fundição do ferro é que há uma clara vitória: triunfa a reivindicação dos trabalhadores referente à abolição dos serões. No entanto, um grupo de fundidores em greve e sócios da Fraternidade Operária acabam por não conseguir ingressar numa das fábricas, ficando sem trabalho. Ante o fato, é decidido pelos dirigentes socialistas edificar uma fábrica social onde os trabalhadores ficavam com o controlo dos meios de produção. Sendo uma iniciativa dos internacionalistas portugueses, José Fontana solicita o contato de Engels a Nobre França para obter informação técnica sobre uma máquina de fresar e um torno em Inglaterra, pedindo ainda "um homem hábil, um engenheiro ou bom operário, em Leeds [que] veja as duas máquinas" ${ }^{\prime 0} \mathrm{em}$ condições para a fábrica social.

Na reunião de 19 de março de 1872, ficava registada na ata do conselho geral da Internacional que Engels havia recebido uma carta de Lisboa, escrita pelo secretário da secção portuguesa, a informar do nascimento da secção da AIT em Lisboa, com "400 membros e três associações afiliadas cujos membros estavam próximos de 1.000" ${ }^{31}$ Além disto, era afirmado ao conselho geral da AIT que em Portugal a adesão à Internacional estava em sintonia com os seus princípios e havia a determinação em lançar a sua divulgação. Neste sentido, tinha sido publicado "um jornal que representava os objetivos e princípios [da Internacional] e pretendia ser um órgão da secção, O Pensamento Social" ${ }^{32} \mathrm{~A}$ carta a dar conta da adesão de Portugal na Internacional fora elaborada a 10 de março, por Nobre França e nela era

30 Carta José Fontana para F. Engels, 24 de janeiro de 1873. In: Karl Marx/Friedrich Engels Papers, 1704, International Institute of Social History, p. 18.

31 INSTITUTE of Marxism-Leninism of the C. C., C. P. S. U. The General Council of the First International 1871-1872 Minutes. Moscow: Progress Publishers, 1964. p. 129.

32 Ibidem. 
reconhecida a adesão tardia da região portuguesa que, "infelizmente era a mais recente na Europa a entrar no grande movimento de emancipação" ${ }^{33}$ da classe trabalhadora. Mais tarde, a 5 de julho de 1872, Engels recebeu uma carta com alguma estatística detalhada sobre a classe operária portuguesa e a informação que "os dirigentes portugueses da AIT afirmaram que estavam totalmente de acordo com as ideias do Conselho Geral". ${ }^{34}$ Em Espanha, o jornal La Emancipación anunciava, a 20 de novembro de 1871, a entrada de Portugal "no movimento operário internacional". ${ }^{35}$

Em outubro de 1873, chega a Espanha uma circular dos internacionalistas portugueses. Nela, era anunciado que "a Federação portuguesa da Associação Internacional dos Trabalhadores acabava de se constituir definitivamente". ${ }^{36} \mathrm{~A}$ federação tinha sido possível com a organização de um conselho regional das três federações locais ligadas à Internacional. Em Inglaterra, era noticiado que a federação portuguesa "contava com mais de 15.000 membros... Só em Lisboa havia 48 secções das associações de resistência". ${ }^{37}$ Pela primeira vez, os internacionalistas portugueses assumem estruturalmente a unidade em nome da Internacional. A 17 de setembro de 1873, a cirular da AIT portuguesa é assinada pelo novo secretário-geral, Azedo Gneco. Este socialista vai ser o homem forte do socialismo português, mantendo os contatos regulares com Marx e Engels e um dos principais dinamizadores no futuro do Partido Socialista em Portugal (1875). No início do mesmo ano, Engels tomava conhecimento do alastramento das ideias da Internacional em Portugal, afirmando que a "organização estava a entrar no Porto". 38

A Internacional simbolizava para o movimento socialista português de 1870 o que a Revolução Francesa e a Primavera dos Povos (1848) tinham simbolizado para a anterior geração socialista. É nessa lógica que percebemos os elogios de $O$ Pensamento Social à AIT: "um dos fenómenos mais singulares do presente século, e talvez de toda a história da humana, é indubitavelmente a Associação Internacional dos Trabalhadores". ${ }^{39}$

\section{Portugal, Paul Lafargue e o Congresso de Haia}

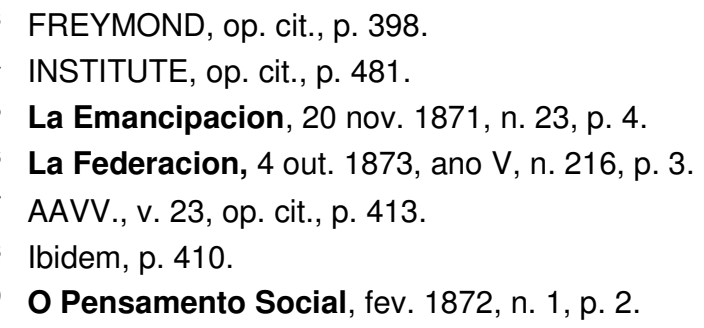


Embora seja inegável o contributo da Aliança na edificação da Internacional em Portugal, a tendência marxista acaba por penetrar no socialismo português, um trabalho alavancado pelo genro de Karl Marx, o socialista franco-cubano Paul Lafargue. O trabalho político de Lafargue na Península Ibérica faz com que Engels designe elogiosamente como o "nosso melhor homem em Madrid". ${ }^{40}$ Paul Lafargue chega a Portugal a 8 de agosto de 1872, acompanhado pela mulher, filha de Karl Marx. Aos olhos de Paul Lafargue, o panorama da Internacional em Portugal era promissor, descrevendo os socialistas portugueses como "inteligentes apesar do seu prudonismo". ${ }^{41} \mathrm{O}$ facto de Lafargue dominar o castelhano ajudava na comunicação com os portugueses, escrevendo a Engels: "Laura e eu dirigimo-nos a eles em espanhol e eles respondem-nos em português". ${ }^{42}$ A presença de Lafargue em Lisboal permite concluir a tentativa de estabelecer um domínio da Aliança em Portugal através do espanhol Morago, no entanto, um grupo de socialistas recusou-se a "publicar o que quer que fosse contra o Conselho Geral". ${ }^{43} \mathrm{O}$ trabalho político de Paul Lafargue em Portugal foi nuclear para o setor marxista, provocando um recuo da influência da Aliança em Portugal. De facto, Paul Lafargue concretizava em Portugal o que não tinha conseguido fazer em Espanha, onde os movimentos operários e socialistas estavam totalmente dominados pela Aliança e os apoiantes do Conselho Geral da AIT eram uma pequena franja.

Além de averiguar a situação do internacionalismo em Portugal, Lafargue tinha uma missão política de extrema importância. Pretendia assegurar o apoio dos socialistas portugueses no congresso de Haia (setembro de 1872), onde ocorreria um confronto entre os apoiantes de Marx e de Bakunin. Os socialistas portugueses relatam a Lafargue que não têm a hipótese de enviar o delegado ao congresso e por isso iam nomear um delegado. Inicialmente, a ideia era empossar Engels como delegado de Portugal, no entanto, essa ideia acabou por não se concretizar. Por isso a escolha recaiu em Paul Lafargue, escolhido como "delegado da federação portuguesa e da nova federação de Madrid". ${ }^{4}$ O socialista francês sugeriu aos portugueses o envio de documentos sobre a situação portuguesa e a apresentação

40 Citado em DERFLER, Leslie. Paul Lafargue and the founding of French Marxism 1842-1882. London: Harvard University Press, 1991. p. 131.

41 Citado em SANTOS, Fernando Piteira. Paul Lafargue e os inícios do movimento socialista em Portugal. In: CHITAS, Eduardo \& RESENDE Hernâni A. (Coord). Filosofia. História. Conhecimento. Homenagem a Vasco de Magalhães-Vilhena. Lisboa: Caminho, 1990.

42 ENGELS, Friedrich. Correspondence [of] Frederick Engels [and] Paul and Laura Lafargue. Moscow: Foreign Languages Pub, 1959-60. p. 423.

43 Ibidem.

44 O Pensamento Social, 13 out. 1872, ano 1, n. 26, p. 2. 
de uma "proposta de dissolução da Aliança e a expulsão de todos os seus membros". ${ }^{45}$ Foi na qualidade de delegado por Portugal que Lafargue apresentou o relatório dos portugueses em Haia. Um relatório elaborado em agosto de 1872, num encontro com os internacionalistas portugueses. $O$ documento estava moldado em fortes críticas ao comportamento da Aliança, uma associação encarada como um conjunto de indivíduos perigosos para a Internacional e para a própria classe operária. Perante esta lógica, o socialismo português apresentava em Haia a proposta de excluir os membros da Aliança da AIT e que ela fosse "declarada uma sociedade perigosa e altamente prejudicial para a emancipação económica da classe trabalhadora". ${ }^{46}$ Segundo os portugueses, a "conduta da Aliança [tinha] originado lamentáveis consequências para o prestígio da Associação Internacional dos Trabalhadores". ${ }^{47}$ No mesmo congresso, é também apresentado um relatório sobre a atividade da Fraternidade Operária, assinada pelo seu secretário, José Fontana.

Em Portugal, a luta política contra a Aliança é mantida no rescaldo do congresso de Haia; através de artigos fornecidos pelo Pensamento Social, é criticada a ação da Aliança no interior de algumas seções da Internacional, demonstrando uma postura contrária ao "espírito da emancipação dos trabalhadores". ${ }^{48}$ No entanto, essa postura perante a Aliança vai ser temporária, com o internacionalismo português a fazer aproximações com o internacionalismo espanhol.

\section{Aproximações e divergências no internacionalismo ibérico}

No impacto do congresso de Haia, os denominados autoritários acabam por consagrar a sua influência em Portugal. Mas a resolução de alteração da sede do Conselho Geral para Nova York vai ser prejudicial e permitir o avanço do setor ligado à Aliança pela Europa. Mikhail Bakunin e, sobretudo, James Guilaume trabalham numa nova vertente internacionalista denominada de autonomista. ${ }^{49} \mathrm{~A}$ ideia era continuar os trabalhos da Internacional na Europa, ocupando o vazio deixado pelo Conselho Geral. Os "autonomistas realizaram o seu 'primeiro' congresso - por eles definidos como o sexto, pois se consideravam os legítimos continuadores da

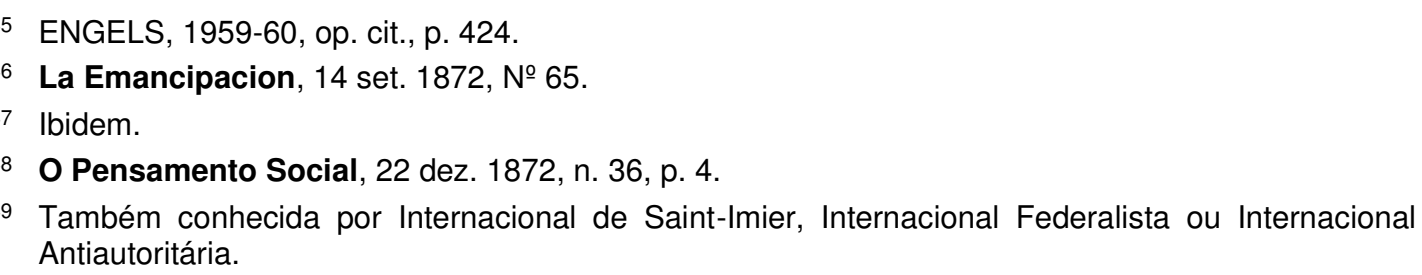


organização - em Genebra", 50 em setembro de 1873. Essa nova corrente foi crescendo em diversos países, com algumas federações a anunciarem publicamente a nulidade das resoluções do congresso de Haia e do Conselho Geral. Em Espanha, este setor estava claramente cimentado, o que vai provocar um aceso debate entre os internacionalistas ibéricos. A 16 de março de 1873, O Pensamento Social publicava um ofício de Francisco Tomás (secretário para o exterior da Federação Regional Espanhola da Internacional). Neste documento, dava conta das resoluções do congresso operário de Córdova, que contrariavam as resoluções do congresso de Haia e solicitava aos portugueses a disponibilidade de "ir ao congresso universal sustentar a integridade dos princípios de liberdade e federação, ou celebrar em continuação o segundo congresso antiautoritário da Internacional". ${ }^{51}$ A resposta dos portugueses não vai ao encontro dos internacionalistas espanhóis. É colocada em causa a legitimidade do congresso de Córdova e a Aliança é acusada de sabotar os trabalhos da Internacional. Deste modo, os internacionalistas portugueses não reconheciam o congresso autonomista. As relações entre os internacionalistas ibéricos estavam extremadas, com os socialistas portugueses a reconhecer a nova Federação Madrilena, controlada por um "grupo [de] marxistas, sem seguidores e um porta-voz para difundir as suas doutrinas, [que] se viu condenado a um forçado silêncio". ${ }^{52}$ Por outro lado, Francisco Tomás afirmava que a maioria dos internacionalistas espanhóis encarava a nova Federação Madrilena como ilegal, escrevendo aos portugueses que ela era um "composto de nove acólitos dos agentes de Mr. Marx" ${ }^{53} \mathrm{O}$ dirigente espanhol invocava no debate 0 nascimento da Internacional em Portugal, lamentando que "talvez os mesmos que formaram parte da Aliança em Lisboa se ocupem em desacreditar uma associação à qual devem o serem internacionais, porque não deveis ignorar que os primeiros internacionais em Lisboa eram aliancistas". ${ }^{54}$ A resposta dos portugueses é feita num ataque feroz à Aliança, uma organização que somente servia a "questões mesquinhas que levantou, as dissidências que promoveu, o desacordo, as divisões, as desconfianças de uns dos outros" ${ }^{55} \mathrm{O}$ conflito entre os internacionalistas ibéricos era do conhecimento de Engels que não deixava de notificar esse acontecimento ao Conselho Geral, fazendo

50 MUSTO, Marcello. Trabalhadores, uni-vos! Antologia política da Primeira Internacional. São Paulo: Boitempo, 2014. p. 81.

51 O Pensamento Social, 16 mar. 1873, ano 2, n. 48, p. 1.

52 TERMES, Josep. Anarquismo y sindicalismo en España: la Primera Internacional (1864-1881). Barcelona: Crítica, 1977. p. 174.

53 O Pensamento Social, 5 abr. 1873, ano 2, n. 51, p. 2.

54 Ibidem, p. 3.

55 Ibidem, p. 2. 
rasgados elogios ao comportamento dos portugueses, pois tinham dado "uma boa resposta"56 às questões da Aliança na Espanha.

No entanto, a correlação de forças no interior do movimento operário internacional é coincidente com um período histórico conturbado em Espanha: em fevereiro de 1873, é implantado um regime republicano, fazendo emergir um pujante e reivindicativo movimento operário dinamizado pelo setor internacionalista, que demonstrava o seu apoio ao novo regime, mas não deixava de "reivindica[r] com mais força as suas pretensões laborais". ${ }^{57}$ É nessa lógica que surge, em julho de 1873, a revolta de Alcoy na Catalunha, na época uma zona com uma elevada taxa de industrialização. A revolta operária é desenvolvida contra o alcaide republicano de Alcoy, que usava a força musculada para reprimir uma greve declarada pelos setores da Internacional. O alcaide Agustí Albors acaba por ser assassinado por uma turba operária e é declarado um Comité de Saúde Público, dirigido por elementos internacionalistas. Vários historiadores observavam esse acontecimento como a Comuna de Paris, em pequena escala e num curto espaço de tempo, pois o exército acaba por dominar e repor a antiga ordem. No entanto, vai ser um acontecimento com forte impacto no espaço mediático internacional, nomeadamente, em Portugal. Diversos jornais portugueses acabam por noticiar os acontecimentos de Alcoy, responsabilizando a Internacional pelo o caos e a destruição na localidade. Perante essa postura, O Pensamento Social veiculava um discurso em defesa dos companheiros espanhóis, negando categoricamente as notícias que davam conta que os "últimos fogos de Lisboa têm sido postos por gente influída da Internacional e pela Comuna". ${ }^{58} \mathrm{~A}$ conturbada realidade externa resulta numa reaproximação dos internacionalistas portugueses aos espanhóis. Esta reaproximação é estimulada pela inércia do Conselho Geral da Internacional, em Nova York, que tinha deixado o recém-nascido internacionalismo português ao abandono. O próprio Engels escreve a Friedrich Adolph Sorge sobre a estagnação da atividade da Internacional. Em finais de 1873, alertava, embora a pseudo Internacional (referência à Internacional Autónoma) estivesse "quieta como um rato",59 "a verdadeira Internacional estava igualmente em silêncio". ${ }^{60}$ Portanto, os recentes acontecimentos políticos em

56 AAVV., v. 23, op. cit., p. 438.

57 REDONDO, Jesús de Felipe. Orígenes y formación del movimiento obrero en España: Una revisón histórica e historiográfica. 2009. Tese (Doutorado em História) - Universidad La Laguna, Santa Cruz de Tenerife, 2009. p. 288.

58 O Pensamento Social, 23 ago. 1873, ano 2, n. 52, p. 3.

59 AAVV. Marx \& Engels Letters 1870-73. v. 44, Marx and Engels 1871-74. [S. I.]: Lawrence \& Wishart Electric Book, 2010. p. 538.

60 Ibidem. 
Espanha vão permitir um apaziguar das relações ibéricas. Os internacionalistas portugueses, na pessoa de Azedo Gneco, escreviam para a La Federación, órgão da Internacional em Barcelona, demonstrando a sua solidariedade, acusando as autoridades locais de usarem o "povo revolucionário ...nas suas manobras políticas". ${ }^{61}$ O socialista James Guillaume confirma essa alteração na Península Ibérica, citando no seu livro um comunicado da seção da Internacional de Lisboa, onde estava patente a solidariedade com "os internacionais espanhóis e, em particular, com os atos da Internacional em Alcoy". 62 Deste modo, há vários contatos entre Portugal e Espanha que indicavam que a "federação portuguesa, que até agora mantinha uma atitude neutra ...parecia disposta a reunir os princípios da autonomia". ${ }^{63}$ De facto, em Espanha surgem nos periódicos operários pedidos de Lisboa a solicitar informações sobre a Internacional, nomeadamente, documentação sobre os congressos de Haia, de Saint-Imier e de "todos aqueles documentos que podem ilustrar o debate entre autoritários e os anarquistas". ${ }^{64}$ Os internacionalistas portugueses demonstravam estar dispostos a rever a sua posição política, fazendo queixas sobre a interrupção da correspondência com o Conselho Geral. Esta falha de comunicação entre Portugal e a Internacional com sede nos EUA é confirmada em carta, pelo próprio Engels, a 14 de junho de 1873, endereçada a Friedrich Adolph Sorge. Engels alertava o secretário-geral do Conselho Geral da AIT que os portugueses estavam descontentes por não receber nenhuma informação da organização, frisando que "ainda assim eles são muito, muito importantes para nós!". ${ }^{65}$ Era importante que Portugal continuasse ao lado do Conselho Geral e não entrasse na órbita da Aliança que dominava totalmente em Espanha, pois marxismo temia que a Península Ibérica ficasse nas mãos dos anarquistas. A Internacional estava fraturada e os socialistas portugueses tinham noção disso, declarando que em Portugal essa ruptura tinha sido danosa no seio da organização, mas que já estava reorganizada e "animada com ideias mais revolucionárias como demonstrava a pronta reaparição de O Pensamento Social'. 66

Em setembro de 1873, ocorre a realização de dois congressos da Internacional, separados por dias, na cidade de Genebra. O sexto congresso da AIT, denominado como centralista, pretendia ser um contraponto ao congresso dos autonomistas. Mais

\footnotetext{
61 La Federacion, 9 ago. 1873, ano 5, n. 208. p. 3.

62 GUILLAUME, op. cit., p. 88.

63 Ibidem, p. 89.

64 La Federacion, op. cit., 23 ago. 1873, ano 5, n. 210. p. 4.

65 AAVV., v. 44, op. cit., p. 507.

66 Ibidem.
} 
uma vez, os socialistas portugueses acordam em estar representados no congresso, noticiando para o público que "a região portuguesa é representada neste congresso dos proletários por A. [Auguste] Serraillier, ex-membro da comuna de Paris e do penúltimo conselho geral, a quem se passou mandato imperativo, para resolver sobre certas questões". ${ }^{67}$ No entanto, o congresso acabou por ser um fracasso, não resolveu os problemas da Internacional e é marcado pela larga ausência de vários delegados; o próprio Conselho Geral decide não enviar nenhum representante de Nova York e o histórico socialista Serraillier, em sintonia com Engels, opta por não comparecer no encontro. O fracasso do congresso não deixa de ser salientado pelos internacionalistas espanhóis, escrevendo para os seus homólogos em Portugal. Informam que, dias antes desse congresso, se tinha realizado na mesma cidade o que na sua ótica era o legítimo congresso da Internacional. Perante a realização de dois congressos publicamente anunciados como representantes legítimos da Internacional, os internacionalistas espanhóis solicitavam aos portugueses uma tomada de postura. Era seu desejo que Portugal acolhesse os resultados saídos do congresso Autónomo, nomeadamente, a proposta de destituir o Conselho Da Geral. No entanto, embora por um determinado momento o socialismo português tenha voltado a reatar íntimos contatos com os internacionalistas espanhóis, rapidamente regressa à esfera do marxismo. No último número de $O$ Pensamento Social, o jornal voltava a atacar a Aliança e realizava um tipo de autocrítica, escrevendo aos leitores que o jornal tinha recente e inadvertidamente fornecido informações erradas e voltava a frisar a sua lealdade ao Conselho Geral e suas propostas. No final do ano de 1873, Karl Marx escrevia uma carta a Thomas Allsop onde categoricamente afirmava "em Lisboa, temos um núcleo de trabalhadores realmente superiores". ${ }^{68}$

\section{Breves considerações finais}

A Primeira Internacional entrou em colapso e morreu como resultado de um confronto interno, mesmo quando ainda havia grandes esperanças de sucesso. $O$ caso de Portugal atesta essa realidade, pois o movimento operário ingressa na AIT num período onde é já visível a sua implosão, embora não deixassem de depositar confiança e esperança no triunfo do internacionalismo. Esse sentimento e vontade política são frutos do aparecimento de um novo leque de jovens socialistas no movimento operário português, que dão tempo de antena na esfera pública a novos

\footnotetext{
O Pensamento Social, 20 set. 1873, Ano 2, n. 54, p. 3.

68 AAVV., v. 44, op. cit., p. 551.
} 
debates em torno da Comuna de Paris e da Associação Internacional dos Trabalhadores. Esses internacionalistas são maioritariamente oriundos da pequena burguesia e da intelectualidade, embora alguns trabalhadores tenham assumido a direção, como é o caso dos tipógrafos Nobre França e Azedo Gneco. É interessante verificar que a Internacional em Portugal é edificada através do internacionalismo, isto é, há a imprescindível influência dos socialistas espanhóis no início, que permite encetar os contatos com os franceses e ingleses, e em simultâneo temos a presença do movimento vários imigrantes e lusodescendentes na direção. É o caso José Fontana, imigrante da Suíça, de Azedo Gneco e José Tedeschi ambos, provavelmente, de descendência italiana.

A posição política e ideológica dos internacionalistas portugueses é instável. Se é verdade que são inicialmente apadrinhados pelos membros da Aliança, rapidamente assumem a defesa das diretrizes do Conselho Geral e do setor marxista. No entanto, as lutas internas da Internacional vão colocar os internacionalistas portugueses na expectativa e não contribuem em nada para a sua formação ideológica. A inércia do Conselho Geral, em Nova York, vai forçar uma reaproximação à Aliança, e desse modo são [re]estabelecidos os contatos com Espanha. Todavia, Portugal era uma região demasiado importante para os marxistas e fundamental para balançar a influência na Península Ibérica; perante isto, os internacionalistas portugueses acabam por regressar à esfera do setor marxista. Entre 1871-73, as novas filiações na Internacional não podiam optar pela neutralidade; as lutas internas na Internacional estavam no auge do confronto e, portanto, era necessário uma tomada de posição política. A ausência de uma identidade ideológica nos primeiros anos da Internacional em Portugal é assumida, mais tarde, pelo homem forte do socialismo português. Azedo Gneco escrevia numa carta a Engels, em 10 de abril de 1876, onde mostrava a história da Internacional em Portugal como tendo sido constituída em 1871 e, à sua luz, "era algo que realmente não era nada". ${ }^{69}$ De facto, Portugal foi uma arena política entre os setores rivais da Internacional que pretendiam assegurar a sua influência nas elites socialistas e no controlo das suas organizações. Durante a sua estada em Lisboa, Paul Lafargue escreve a Engels que teve conhecimento da circulação em Portugal de uma carta do "Papa Bakunin"70 onde ataca o Conselho Geral. Embora o socialismo português acabasse por apoiar o lado de Karl Marx, não é possível afirmar que esse fosse totalmente marxista. Em 1873, Nobre França relatava a Engels que já tinha escrito a

\footnotetext{
69 OLIVEIRA, César de. 13 Cartas de Portugal para Engels e Marx. Lisboa: Iniciativas Editoriais, 1978. p. 60.

70 ENGELS, 1959-60, op. cit., p. 423.
} 
Karl Marx para agradecer a oferta do exemplar do livro $O$ capital. O socialista português garante que esse importante livro estava a ser bem acolhido em Lisboa, os exemplares eram requisitados na livraria Internacional de Carrilho Videira. Nobre França fornece a informação que Carrilho tinha encomendado 100 exemplares e os compradores faziam a sua aquisição de forma sorrateira e em voz baixa, pois era uma livraria com "fama de revolucionária, de internacionalista" ${ }^{71}$ O marxismo não era totalmente desconhecido, mas faltava uma análise mais profunda e esse estava longe de ser dominante no pensamento socialista português, pois as ideias de outros pensadores socialistas continuavam a gravitar no movimento operário português, como era o caso de um Proudhon, Fourier, Louis Blanc e Bakunin.

Recebido em 31/07/2019

Aprovado em 02/10/2019

71 Carta Nobre França para F. Engels, 17 de agosto de 1873. In: Hermann Jung Papers, 670, International Institute of Social History, p. 44. 